\title{
Ad-induced affect: The effects of forewarning, affect intensity, and prior brand attitude
}

\author{
SANG Y. LEE
}

sang.lee@mail.wvu.edu

Follow this and additional works at: https://researchrepository.wvu.edu/faculty_publications

Part of the Mass Communication Commons

\section{Digital Commons Citation}

LEE, SANG Y., "Ad-induced affect: The effects of forewarning, affect intensity, and prior brand attitude" (2010). Faculty Scholarship. 1168.

https://researchrepository.wvu.edu/faculty_publications/1168

This Article is brought to you for free and open access by The Research Repository @ WVU. It has been accepted for inclusion in Faculty Scholarship by an authorized administrator of The Research Repository @ WVU. For more information, please contact ian.harmon@mail.wvu.edu. 
This article was downloaded by: [Lee, Sang]

On: 30 July 2010

Access details: Access Details: [subscription number 924971924]

Publisher Routledge

Informa Ltd Registered in England and Wales Registered Number: 1072954 Registered office: Mortimer House, 3741 Mortimer Street, London W1T 3JH, UK

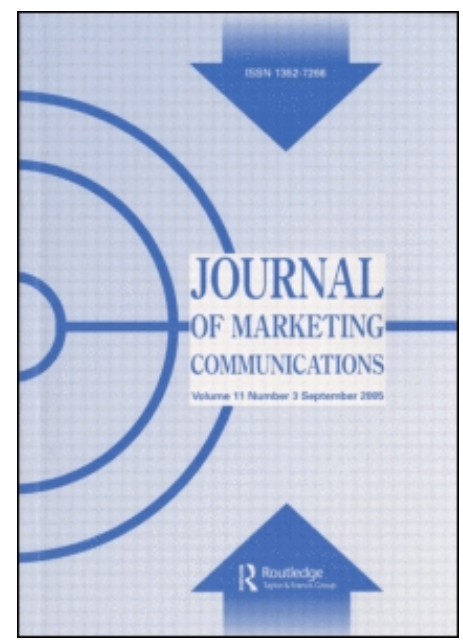

\section{Journal of Marketing Communications}

Publication details, including instructions for authors and subscription information:

http://www.informaworld.com/smpp/title content=t713704530

\section{Ad-induced affect: The effects of forewarning, affect intensity, and prior brand attitude}

Sang Yeal Lee

P.I. Reed School of Journalism, West Virginia University, Morgantown, WV, USA

First published on: 26 February 2010

To cite this Article Lee, Sang Yeal(2010) 'Ad-induced affect: The effects of forewarning, affect intensity, and prior brand attitude', Journal of Marketing Communications, 16: 4, 225 - 237, First published on: 26 February 2010 (iFirst)

To link to this Article: DOI: $10.1080 / 13527260902869038$

URL: http://dx.doi.org/10.1080/13527260902869038

\section{PLEASE SCROLL DOWN FOR ARTICLE}

Full terms and conditions of use: http://www.informaworld.com/terms-and-conditions-of-access.pdf

This article may be used for research, teaching and private study purposes. Any substantial or systematic reproduction, re-distribution, re-selling, loan or sub-licensing, systematic supply or distribution in any form to anyone is expressly forbidden.

The publisher does not give any warranty express or implied or make any representation that the contents will be complete or accurate or up to date. The accuracy of any instructions, formulae and drug doses should be independently verified with primary sources. The publisher shall not be liable for any loss, actions, claims, proceedings, demand or costs or damages whatsoever or howsoever caused arising directly or indirectly in connection with or arising out of the use of this material. 


\title{
Ad-induced affect: The effects of forewarning, affect intensity, and prior brand attitude
}

\author{
Sang Yeal Lee* \\ P.I. Reed School of Journalism, West Virginia University, 304 Martin Hall, Morgantown, \\ WV 26506, USA
}

\begin{abstract}
Emotion in marketing communication is important because it influences the manner consumers process information. Using emotional appeal ads, a between-subjects experiment was conducted to examine the role of forewarning of persuasive intent, affect intensity, and prior attitude. Results indicate that forewarning of persuasive intent of the advertiser had negative attitudinal effects on the dependent variables regardless of experimental conditions. Forewarning of persuasive intent had negative attitudinal effects even among participants who had positive attitudes toward the company, and those who had high affect intensity. Results also indicate that participants who already had negative attitudes toward the brand were not influenced by ad-induced affect.
\end{abstract}

Keywords: affect; emotion; forewarning; prior attitude

\section{Introduction}

Use of emotion is a popular strategy to deliver persuasive messages to consumers. Emotional reactions to persuasive messages are important in the marketing communication context because emotional feelings can occur quickly and influence the manner information is processed. Research has shown that emotional feelings induced by ads influence consumers' evaluations to the brand (Edell and Burke 1987), increase their attention to the content of the ad (Olney, Holbrook, and Batra 1991), and influence brand attitudes (Aaker et al. 1986).

Research has shown that affect (i.e. a feeling or emotion as distinguished from cognition, thought, or action) can be a powerful factor changing consumers' attitudes in persuasive communication (Dolores and Tarcan 2003). Affect has been shown to motivate information processing and may be linked to the extent of deliberative efforts (Peters, Lipkus, and Diefenbach 2006). Some researchers further suggest that affect formed during the processing of a persuasive message can become information by informing us about others, and our judgment can be made based on affect we feel about an object (Schwarz and Clore 1983). This 'affect as information' is based on an observation that people often base their evaluation of an object on the affective reactions they are experiencing at the time of evaluation (Schwarz and Clore 1983). Consequently, people might evaluate an object more favourably when they are feeling happy rather than when they are not. In other words, the feelings that they are experiencing are used as information in evaluating the object. Pham (1998), for example, showed that people used their affective feelings as a direct basis for evaluating a product when they were told to make

\footnotetext{
*Email: Sang.Lee@mail.wvu.edu
} 
a judgment to which affective reactions were relevant. When participants were asked to use utilitarian information, however, the affect they experienced had no impact on their judgments.

In the context of advertising, however, affective reactions can also be moderated by other critical variables to influence the effectiveness of the message. For example, affective feelings may quickly change once people know the intent of the advertiser who wants to change their attitudes. Individuals may also react differently toward the emotional stimuli, depending upon their level of attitudes toward the brand. For example, if the consumer dislikes the brand, the affective feelings induced by an ad may not lead to higher advertising effectiveness. Individuals' affective intensity is also known to influence message effectiveness (Geuens and de Pelsmacker 1999), such that individuals with high affective intensity tend to be more responsive toward the emotional ads. This research examines the role of ad-induced affect and how it interacts with intent of the advertiser, prior attitude toward the brand, and affect intensity. More specifically, the objective of the current study is to understand the effects of ad-induced affect when the intent of the advertiser is known among individuals who have different levels of brand attitudes and affect intensity.

\section{Theoretical background and hypotheses}

\section{Forewarning of persuasive intent}

Research in persuasion provides ample evidence that knowing the intent of a persuasive message can influence individuals' processing of the information (McGuire 1961, 1962; McGuire and Papageorgis 1961, 1962; Petty and Cacioppo 1977, 1979; Chen et al. 1992). It is a robust finding that the persuasive intent of the message sender can directly influence information processing of the receiver. For example, research has shown that forewarning of persuasive intent can lead to resistance to persuasive messages (McGuire and Papageorgis 1962; Petty and Cacioppo 1977, 1979; Chen et al. 1992). Papageorgis (1968) demonstrated that forewarning of the incoming message that is different from the individuals' belief can bolster individuals' existing belief, possibly by generating and rehearsing counterarguments. These anticipatory cognitive responses (e.g. counterarguments) tend to lead to resistance to the subsequent persuasion attempt (Petty and Cacioppo 1977). Thus, persuasion research generally suggests that individuals' information processing can differ if the persuasive intent of the message sender is known to message receivers.

The role of persuasive intent is particularly important in marketing communication because communication efforts must often be made in a situation where the persuasive intent of the company is clear to consumers. For example, a company may launch an advertising campaign designed to counter negative attitudes that have been formed due to a product recall. In this case, consumers who were informed about the product recall likely know the intent of the advertiser. In such a case, the impact of the advertising campaign can significantly decrease because, as prior research suggests (Petty and Cacioppo 1977), knowing the persuasive intent of the message sender can serve as a cue to develop counterarguments during the message processing. Thus, the following hypotheses are developed:

H1: Individuals will have significantly lower (a) ad attitude, (b) brand attitude, and (c) perceived persuasiveness when persuasive intent is forewarned (vs not forewarned). 


\section{Affect intensity and forewarning of persuasive intent}

Emotion plays an important role in the process of resistance or acceptance to persuasion (Pfau et al. 2001) by directly influencing people's information processing. Research has shown that affective responses from persuasive messages play a greater role than cognitive responses in forming attitudes (Bower 1981; Moore, Harris, and Chen 1994; Geuens and de Pelsmacker 1999; Kim and Morris 2007). Bower (1981), for example, suggests that the affect toward an object can be conceived as having a specific node in memory, connected with other aspects of the emotion via an associative network. This specific affect can then be activated when the individual is faced with the relevant stimulus, which in turn can influence the manner people process the information.

However, individuals' level of affect intensity (AI) can be different. AI can be defined as 'stable individual differences in the strength with which individuals experience their emotions' (Larsen and Diener 1987). Some individuals are more affective or emotional than others by nature. Research suggests that individual differences in the level of affect intensity influence the affective as well as cognitive responses to emotional stimuli (Moore et al. 1994; Geuens and de Pelsmacker 1999). For example, people with high AI tend to show more positive feelings and cognitions toward emotional messages. Geuens and de Pelsmacker (1999) showed that people with high AI paid more attention and reported higher attitudes toward the emotional messages than those with lower AI. Research also indicated that high AI individuals react more negatively toward the negative emotional messages than low AI individuals (Moore et al. 1994).

Individuals with different AI levels may react to emotionally persuasive messages differently, depending upon whether the persuasive intent is known before or during the processing of messages. For example, it is likely that high AI individuals will display higher resistance to persuasion and view the emotional message more negatively and less persuasively when the persuasive intent is forewarned. This is because individuals are likely to know that the advertiser is purposely using emotion to achieve certain goals. On the contrary, high AI individuals without forewarning will display higher levels of affective feelings and evaluate the emotional message more positively, as prior research reports (Bower 1981; Moore et al. 1994; Kim and Morris 2007). Among low AI individuals, however, any significant positive or negative responses are not likely to emerge since their affective responses to the emotional message are expected to be low. As a result, the impact of ad-induced affect will be low among low AI individuals. Based on the foregoing discussion, the following interaction hypotheses are proposed:

$\mathrm{H}$ 2: When persuasive intent is forewarned (vs not forewarned), high AI individuals are expected to have lower (a) ad attitude, (b) brand attitude, and (c) perceived persuasiveness, whereas no such differences are expected for low AI individuals.

Research has shown that individuals can form both positive and negative attitudes simultaneously when processing persuasive messages (Kaplan 1972; Ahluwalia, Burnkrant, and Unnava 2000). Attitudes that have both positive and negative ('ambivalent') components can be used to assess the individuals' reactions toward a stimulus (Kaplan 1972). Prior research (Ahluwalia et al. 2000) suggests that attitude change pertaining to negative information can be better assessed through attitudinal ambivalence measures instead of the standard attitudinal valence measures. Attitudinal ambivalence is important in persuasive communication because higher levels of ambivalence tend to be positively associated with weaker attitude-behaviour 
relationships and greater attitudinal pliability (see Crano and Prislin 2006, for discussion of attitudinal ambivalence).

Attitudinal ambivalence can be influenced by forewarning of persuasive intent among AI individuals. Specifically, while high AI individuals react positively toward an emotional message, they will also respond negatively if the persuasive intent is known, compared to when such intent is not known. On the other hand, those with low AI are likely to respond to an emotional message more calmly or less emotionally and, therefore, low AI individuals will experience less fluctuation in terms of the attitudinal evaluations toward the emotional message. Thus, the following ambivalence hypothesis is proposed:

H3: When persuasive intent is forewarned (vs not forewarned), high AI individuals are expected to have significantly more ambivalent attitudes, whereas no such differences in attitudinal ambivalence are expected for low AI individuals.

\section{Prior brand attitude and forewarning of persuasive intent}

Research suggests that existing attitudes can directly influence the processing of a persuasive message (Chattopadhyay and Basu 1990). For example, consumers are likely to be more receptive to and less critical of the persuasive message for a brand for which they have positive attitudes. It is also likely that the level of resistance to persuasion can be low when consumers have positive attitudes toward a brand. This is perhaps because the persuasive message is consistent with the message recipient's existing brand attitudes. Conversely, when the individual's existing brand attitudes are negative, the persuasive message is inconsistent with the existing attitudes and, thus, the individual is more likely to generate counterarguments against the persuasive message. Accordingly, the resultant evaluations will be negative.

Although individuals who have positive attitudes toward a brand are expected to be receptive to the persuasive message from that brand, forewarning of persuasive message can still influence their information processing. Research suggests that a simple forewarning of the persuasive intent of a message sender tends to increase resistance to persuasion, irrespective of the level of discrepancy of message (Campbell 1995). Thus, even those individuals who have positive attitudes are likely to display lower message effectiveness when the persuasive intent is forewarned than when such intent is not forewarned. On the contrary, forewarning of persuasive intent is not likely to make significant differences among individuals who have negative attitudes toward the brand. This is because, whether the persuasive intent is forewarned or not, they will generate counterarguments when processing the persuasive message inconsistent with their attitudes. Based on the preceding discussion, the following hypotheses are proposed:

H4: Persuasive intent will interact with prior attitude such that individuals who have positive attitudes toward the target brand will report lower (a) ad attitude, (b) brand attitude, and (c) perceived persuasiveness when persuasive intent is forewarned (vs not forewarned), while such differences will not be evident among those who have negative or neutral attitudes.

\section{Method}

\section{Overview and participants}

Several pretests were conducted to select the brand and to develop the stimulus materials. The research used a real existing brand that was known to the study participants in order to increase external validity. One hundred and sixty students from a major Mid-Eastern university in the United States participated in the main experiment for extra credit. 


\section{Selection of brand}

The first pretest was conducted to select the brand with two guidelines in mind. First, the brand has to be well known among the study participants such that they already have existing attitudes toward the brand. Second, the study participants should have a fairly wide distribution of attitude scores toward the brand. These two were necessary to examine the impact of a campaign ad among participants with different levels of attitudes toward the brand. Based on these guidelines, six brands were initially selected and subsequently tested on attitudinal dimensions $(N=45)$. As a result, Wal-Mart was selected as the brand to be used in the study because of the brand familiarity and a wide distribution of attitude scores. The attitude scores toward Wal-Mart were widely distributed among the pretest participants in terms of bad/good $(M=4.91, \mathrm{SD}=1.56)$, harmful/beneficial $\quad(M=5.13, \quad \mathrm{SD}=1.55), \quad$ desirable/undesirable $\quad(M=4.80$, $\mathrm{SD}=1.55)$, and awful/nice $(M=4.80, \mathrm{SD}=1.42)$ with Cronbach's alpha of 0.96 .

\section{Stimulus ads}

Initially 10 emotional stories were selected from several websites and a group of advertising major students $(N=10)$ subsequently evaluated the stories for emotional content. Then, three stories were selected to be used in the study. The stories were edited to have similar story length (about 450 words) and to fit into a one-page ad. Additionally, one rational appeal ad containing a story of an energy conserving effort was developed for comparison purposes. The four test ads (three emotional ads and one rational appeal ad) contained a headline, an emotional or rational story, and one paragraph describing the company's social contribution relevant to the story. The brand in the pretest ads was an unknown brand to the study participants to avoid any familiarity effects. The four ads were tested and compared in a pretest $(N=47)$ using an eight-item, seven-point Likert type scale (affectionate, concerned, emotional, hopeful, kind, moved, sentimental, and warmhearted: Cronbach's $\alpha=0.93$ ), drawn from Edell and Burke's (1987) measure of warm feelings. As a result, the ad containing a story describing a family of four small children celebrating Christmas was selected as the test ad because it was significantly more emotional than the rational ad $(p<.001)$, and because it scored higher than the other emotional ads in terms of Edell and Burke's (1987) measure of warm feelings.

\section{Procedure}

First, participants were briefed and signed the informed consent prior to conducting the study. Participants were then informed that they were to participate in two 'unrelated' studies and given two booklets. The first booklet, ostensibly disguised as a 'student lifestyle survey' by the Student Housing and Wellness Center, contained the questions about participants' existing attitudes toward several brands, including the target brand Wal-Mart. The first booklet also contained 20 affect intensity questions, which also served as a distraction task before seeing the stimulus ad. The second booklet contained the forewarning manipulation message, stimulus ad, and the dependent variable questions. Half of the participants received the booklet with a forewarning message, while the other half received the booklet with no forewarning message. Participants read the message first, then saw the stimulus ad, and finally filled out the questionnaire. 


\section{Independent variables}

In this study, forewarning of persuasive intent was manipulated through a message in the cover of the second booklet. Participants in the forewarning group read the following message:

Wal-Mart has been under negative publicity from the mass media for various reasons and, as a result, the public may have negative attitudes or opinion toward Wal-Mart. The ad you will be reading in the next page is designed to counter negative images toward Wal-Mart.

On the other hand, participants in no forewarning group read the following message:

You will be reading an ad in the next page. We would like you to normally read the ad as if you are reading an ad in a magazine or newspaper.

Prior attitude and $A I$ were the two measured independent variables. The first booklet contained questions for each of these variables. Prior attitude was measured using a six-item semantic differential scale anchored by good/bad, socially responsible/socially irresponsible, beneficial/harmful, desirable/undesirable, ethical/unethical, and awful/nice $(\alpha=0.93)$. Participants had a fairly wide distribution of attitude scores $(M=28.4$, $\mathrm{SD}=8.68)$ on the target brand, Wal-Mart. Participants were later separated into three attitude groups (positive, neutral, and negative) based on the attitudinal scores for data analysis.

AI was measured using a 20-question affect scale $(\alpha=0.92)$ developed and tested by Geuens and de Pelsmacker (2002). A median split was used to separate the participants into low vs high affect intensity groups.

\section{Dependent variables}

The study employed four dependent measures. Ad attitude was measured with a three-item, seven-point semantic differential scale, anchored by I disliked the ad/I liked the ad, I reacted unfavorably to the ad/I reacted favorably to the ad, and the ad was bad/the ad was good $(\alpha=0.94)$, drawn from Holbrook and Batra (1987). Brand attitude was measured by a fouritem, seven-point semantic differential scale, anchored by good/bad, beneficial/harmful, desirable/undesirable, and nice/awful $(\alpha=0.92)$, used by Ahluwalia (2002). Measures of ambivalence of attitude followed Kaplan's (1972) technique as used by Ahluwalia et al. (2000). Respondents were asked to rate on a seven-point scale (not at all, 0, to extremely, 6) the extent to which they had positive feelings toward the brand and the extent to which they had negative feelings toward the brand. Ambivalence of attitude was computed by taking the sum of the positive and negative ratings of the attitude toward the object and then subtracting the absolute value of the difference between the two scales. This measure of ambivalence of attitude was proven reliable in prior research (see Kaplan 1972; Ahluwalia et al. 2000). Finally, perceived persuasiveness of the message was measured with a four-item, seven-point differential scale, anchored by very weak/very strong, not very convincing/very convincing, not very powerful/very powerful, and not very persuasive/ very persuasive $(\alpha=0.95)$, adopted from Gurhan-Canli and Maheswaran (2000).

\section{Results}

Results are assessed by a series of 2 (forewarning of persuasive intent: forewarning vs no forewarning) $\times 3$ (prior attitudes toward the brand: positive vs neutral vs negative) $\times 2$ (affect intensity: high vs low) ANOVAs. Forewarning of persuasive intent was a manipulated between-participant variable and prior attitude toward the brand and AI were 
the measured independent variables. Means and standard deviations are presented in Tables 1 and 2. ANOVA results are presented in Table 3.

$\mathrm{H} 1$ predicted that forewarning of persuasive intent would have a negative impact on (a) ad attitude, (b) brand attitude, and (c) perceived persuasiveness. Consistent with prior research (McGuire and Papageorgis 1962; Chen et al. 1992), participants in the forewarning group reported lower ad attitude, $F(1,148)=16.56, p<.001$, partial $\eta^{2}=0.10$, brand attitude, $F(1,148)=7.31, p<.01$, partial $\eta^{2}=0.05$, and perceived persuasiveness, $F(1,148)=4.13, p<.05$, partial $\eta^{2}=0.03$. Thus, H1a, b, and c were supported.

$\mathrm{H} 2$ predicted that AI will interact with forewarning of persuasive intent on (a) ad attitude, (b) brand attitude, and (c) perceived persuasiveness such that, when persuasive intent is forewarned, high AI participants would display lower ad attitude, brand attitude and perceived persuasiveness. ANOVA analyses indicated that the interaction between AI and forewarning was significant on ad attitude, $F(1,148)=8.74, p<.01$, partial $\eta^{2}=0.06$, brand attitude, $F(1,148)=5.29, p<.05$, partial $\eta^{2}=0.03$, and perceived persuasiveness, $F(1,148)=4.71, p<.05$, partial $\eta^{2}=0.03$. Simple effect tests showed that forewarning of persuasive intent led to lower ad attitude, $M_{\text {forewarning }}=3.97$ versus $M_{\text {no-forewarning }}=5.84, t=5.37, p<.001$, lower brand attitude, $M_{\text {forewarning }}=4.53$ versus $M_{\text {no-forewarning }}=5.75, t=4.34, p<.001$, and lower perceived persuasiveness, $M_{\text {forewarning }}=4.04$ versus $M_{\text {no-forewarning }}=5.26, t=3.43, p<.01$, among high AI individuals. Such differences, however, were not observed among low AI individuals (all $p$ values $>.05$ ). Thus, $\mathrm{H} 2 \mathrm{a}, \mathrm{b}$, and $\mathrm{c}$ were supported.

H3 predicted that, when persuasive intent is forewarned (vs when not forewarned), high AI participants would show significantly more ambivalent attitudes, whereas such differences are not expected for low AI participants. As predicted, high AI individuals in forewarning conditions showed more ambivalent attitudes among high AI participants, $F(1,148)=6.58, p<.01$, partial $\eta^{2}=0.04$. Simple effect tests showed that forewarning of persuasive intent led to significantly more ambivalent attitude, $M_{\text {forewarning }}=9.88$ versus $M_{\text {no-forewarning }}=6.32, t=3.64, p<.01$, whereas such difference was not observed among low AI participants (all $p>.05$ ). Thus, H3 was supported.

$\mathrm{H} 4$ predicted that persuasive intent would interact with prior attitude such that participants who have positive attitude toward the target brand are likely to have lower (a) ad attitude, (b) brand attitude, and (c) perceived persuasiveness when persuasive intent is forewarned, while such differences are not likely among those who have negative or neutral attitudes. Data analysis results showed that the interaction between forewarning and prior brand attitude was significant on ad attitude, $F(2,148)=3.27, p<.05$, partial $\eta^{2}=0.04$, and on perceived persuasiveness, $F(2,148)=3.11, p<.05$, partial $\eta^{2}=0.04$. Post hoc analyses showed that participants who had positive brand attitudes displayed lower ad attitude, $M_{\text {forewarning }}=4.53$ versus $M_{\text {no-forewarning }}=6.28, t=4.70, p<.01$, brand attitude, $M_{\text {forewarning }}=5.25$ versus $M_{\text {no-forewarning }}=6.10, t=2.74, p<.01$, and perceived persuasiveness, $M_{\text {forewarning }}=4.53$ versus $M_{\text {no-forewarning }}=5.60$, $t=3.10, p<.01$, when persuasive intent was forewarned than when not forewarned. However, forewarning of persuasive intent did not make a significant impact among those who had neutral or negative attitudes toward the target brand across all hypothesized dependent variables (all $p>.05$ ). Thus, $\mathrm{H} 4 \mathrm{a}, \mathrm{b}$, and $\mathrm{c}$ are supported. 


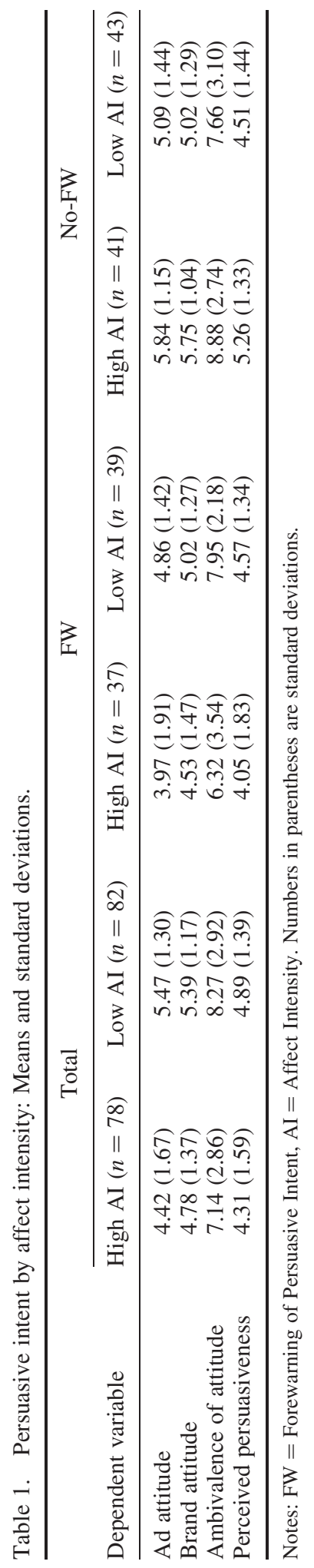




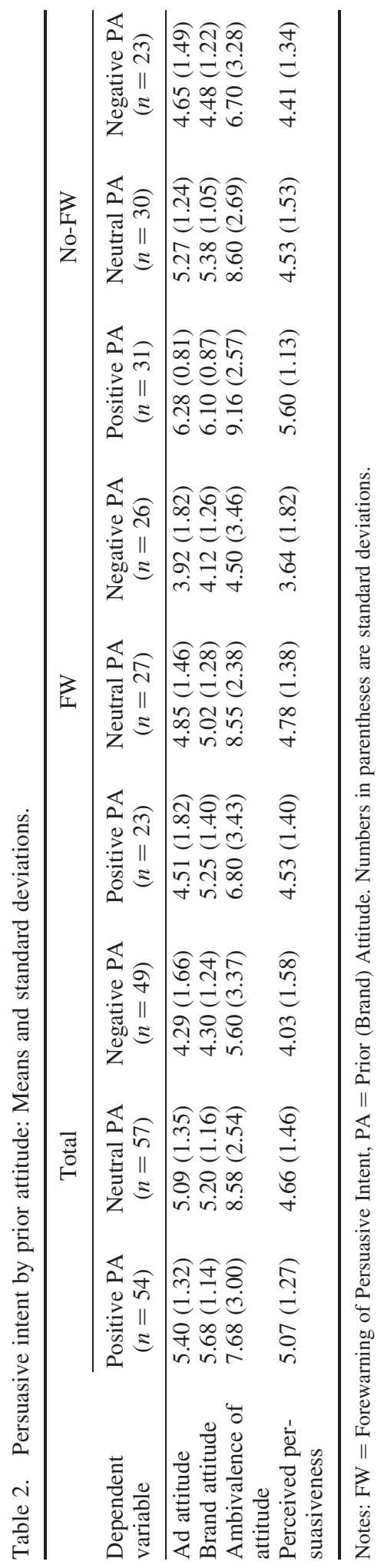


Table 3. Effects of persuasive intent, affect intensity, and prior brand attitude.

\begin{tabular}{lcccc}
\hline & \multicolumn{4}{c}{ ANOVA $(F$-value $)$} \\
\cline { 2 - 5 } Source & Ad attitude & $\begin{array}{c}\text { Brand } \\
\text { attitude }\end{array}$ & $\begin{array}{c}\text { Ambivalence } \\
\text { of attitude }\end{array}$ & $\begin{array}{c}\text { Perceived } \\
\text { persuasiveness }\end{array}$ \\
\hline FW & $16.56 * * *$ & $7.31 * *$ & $4.07 *$ & $4.13 *$ \\
AI & 0.27 & 0.39 & 0.11 & 0.28 \\
PA & $5.16 * *$ & $14.20 * * *$ & $8.03 * * *$ & $4.47 *$ \\
FW $\times$ AI & $8.75 * *$ & $5.29 *$ & $6.58 *$ & $4.71 *$ \\
AI $\times$ PA & 0.23 & 0.08 & 0.29 & 0.59 \\
FW $\times$ PA & $3.27 *$ & 0.57 & $3.11 *$ & 0.43 \\
FW $\times$ AI $\times$ PA & 2.37 & 1.16 & $3.01 *$ & $3.36 *$ \\
\hline
\end{tabular}

$* p<.05 ; * * p<.01 ; * * * p<.001$.

\section{Conclusion}

\section{Discussion and implications}

The current research examined the role of ad-induced affect and how it interacted with forewarning of persuasive intent, prior attitudes, and affect intensity. The current research adds knowledge to our understanding of emotion in persuasion.

Consistent with prior research in persuasion, this research clearly indicates the negative impact of forewarning of persuasive intent. Forewarning of persuasive intent of the advertiser led to lower advertising effectiveness across the dependent variables. Forewarning of persuasive intent also interacted with prior attitude and AI. For example, participants who had positive prior attitude toward the target brand displayed favorable reactions to the emotional ad. However, when participants were warned of the persuasive intent of the message, they reacted negatively toward the ad. This result implies that forewarning of persuasive intent can generate resistance to persuasion even among individuals with positive prior brand attitudes who are expected to have less resistance to persuasion.

Also, high AI individuals evaluated the emotional ad favorably when persuasive intent was not forewarned. However, high AI individuals evaluated the ad more negatively than low AI individuals when the persuasive intent was revealed. This result indicates that, compared to low AI individuals, high AI individuals have high resistance to persuasion on the affect-inducing ad if the persuasive intent of the advertiser is forewarned.

Forewarning of persuasive intent also interacted with AI on ambivalence. As predicted, when persuasive intent was forewarned (vs when not forewarned), high AI participants showed significantly more ambivalent attitudes, whereas such differences were not observed for low AI participants. This result clearly suggests that high AI individuals can be more influenced by ad-induced affect than low AI individuals.

The results of the study also indicate that consumers' existing negative attitudes are difficult to change with ad-induced affect. Compared to those who had neutral or positive attitudes, individuals who had negative attitudes toward the target brand were not influenced by ad-induced affect, regardless of experimental conditions.

Based on the results of the study, practitioners may want to design the persuasive message in such a way that the persuasive intent is not overtly evident. Although it is reasonable to assume that consumers would be aware of, at least to some extent, the persuasive intent of any persuasive message, this study indicates that if consumers are consciously aware of the persuasive intent during message processing, the effectiveness of the message can significantly decrease. Along the same lines, this study also suggests that, 
consistent with prior research (Weinberger, Allen, and Dillon 1981), a persuasive effort directly rebutting or countering negative information may not be effective since in such a case, consumers would clearly know the persuasive intent in the message. Thus, companies that are trying to improve image in the market may develop a strategy to reach out to consumers without revealing the persuasive intent.

The study also confirmed that, depending upon the individual's affect intensity, message effectiveness can differ. For practitioners, marketing communication messages that induce affective feelings may not be appropriate for people with low AI. On the contrary, affect-inducing ads can positively influence attitudes of people with high AI. The results further suggest that consumers' negative attitudes toward the brand or company can be difficult to change. The ad-induced affect in this study had virtually little impact among participants with negative attitudes toward the target brand.

\section{Limitations and future research}

The study has several limitations. First, in this study a print (magazine) ad was used as the stimulus material. Print media might not be ideal in terms of stimulating affective feelings, compared to, for example, radio or television that use audio and/or video. Because print ads with limited graphics were used in this study, it is possible that some participants may have been short of generating affective feelings.

Second, participants in this study were college students. It is likely that, compared to the general public, college students are more aware and critical of business practices by companies such as Wal-Mart. Accordingly, they may process persuasive messages in a different manner from the general public. Thus, cautions should be exercised in interpreting the results.

Third, the current research dealt with a store (Wal-Mart) rather than a product brand. Consumers' schema toward a store brand may be different from a product brand because consumers' attitudes toward a store brand can be the result of various experiences such as advertising, store visits, product use, and so on.

Future research may benefit by employing other critical variables such as repetition of the persuasive message. The impact of affect can differ, depending upon how many times the consumer is exposed to the emotionally persuasive message. It will be especially interesting to see if repetition of an emotional ad can change the attitudes of those who have negative attitudes toward the brand as well as those who have low AI.

Secondly, future research can also benefit by examining the role of product involvement. For example, past research in persuasive communication (Petty and Cacioppo 1979; Chen et al. 1992) has shown that resistance to persuasion tends to be high when product involvement is high. Thus, it is possible that emotional appeals in marketing communication may have an impact even among consumers who have negative attitudes toward the brand when the product involvement is low.

Finally, another intriguing avenue would be to examine the differences between genders. Research generally suggests that females tend to be more influenced by emotional stimuli. Although not specifically hypothesized in this study, females may respond more favorably to affect-inducing ads. It would be especially interesting to see if females with negative attitudes toward the brand were influenced by ad-induced affect.

In conclusion, despite the limitations, the results of the study add knowledge to our understanding of affective feelings in persuasion. The current research suggests that practitioners need to understand the role of affect under different conditions to make the marketing communication more effective. 


\section{Notes on contributor}

Sang Yeal Lee $(\mathrm{PhD})$ is an Assistant Professor and Chair of Advertising Sequence in the Perley Isaac Reed School of Journalism at the West Virginia University. Prior to beginning his academic career, he was a manager of advertising in a Fortune 500 company and also worked for a multinational advertising agency as an account executive. This study was funded in part by the Perley Isaac Reed School of Journalism at West Virginia University.

\section{References}

Aaker, D., D. Stayman, and M. Hagerty. 1986. Warmth in advertising: measurement, impact, and sequence effects. Journal of Consumer Research 12: 365-381.

Ahluwalia, R. 2002. How prevalent is the negativity effect in consumer environment? Journal of Consumer Research 29, September: 270-9.

Ahluwalia, R., R. Burnkrant, and H. Unnava. 2000. Consumer response to negative publicity: The moderating role of commitment. Journal of Marketing Research 37, May: 203-14.

Bower, G.H. 1981. Mood and memory. American Psychologist 36, no. 2: 129-48.

Campbell, M. 1995. When attention-getting advertising tactics elicit consumer inferences of manipulative intent: The importance of balancing benefits and investments. Journal of Consumer Psychology 4, no. 3: 225-54.

Chattopadhyay, A., and K. Basu. 1990. Humor in advertising: The moderating role of prior brand evaluation. Journal of Marketing Research 32, November: 466-76.

Chen, H., R. Reardon, C. Rea, and D. Moore. 1992. Forewarning of content and involvement: Consequences for persuasion and resistance to persuasion. Journal of Experimental Social Psychology 22, no. 3: 22-33.

Crano, W., and R. Prislin. 2006. Attitudes and persuasion. Annual Review of Psychology 57: $347-74$.

Dolores, A., and K. Tarcan. 2003. Affect as information in persuasion: A model of affect identification and discounting. Journal of Personality and Social Psychology 84, no. 3: 453-69.

Edell, J., and M. Burke. 1987. The power of feelings in understanding advertising effects. Journal of Consumer Research 14, December: 421-33.

Geuens, M., and P. de Pelsmacker. 1999. Affect intensity revisited: Individual differences and the communication effects of emotional stimuli. Psychology and Marketing 16, no. 3: 195-209.

- 2002. Developing a short affect intensity scale. Psychological Reports 91, no. 2: 657-70.

Gurhan-Canli, Z., and D. Maheswaran. 2000. Determinants of country-of-origin evaluations. Journal of Consumer Research 27, no. 1: 96-101.

Holbrook, M., and R. Batra. 1987. Assessing the role of emotions as mediators of consumer responses to advertising. Journal of Consumer Research 14, December: 404-20.

Kaplan, K. 1972. On the ambivalence-indifference problem in attitude theory and measurement: A suggested modification of the semantic differential technique. Psychological Bulletin 77, May: $362-72$.

Kim, J., and J. Morris. 2007. The power of affective response and cognitive structure in product-trial attitude formation. Journal of Advertising 36, no. 1: 95-106.

Larsen, R., and E. Diener. 1987. Affect intensity as an individual difference characteristic: A review. Journal of Research in Personality 21, no. 1: 1-39.

Maheswaran, D., and J. Meyers-Levy. 1990. The influence of message framing and issue involvement. Journal of Marketing Research 27, no. 3: 361-7.

McGuire, W. 1961. The effectiveness of supportive and refutational defenses in immunizing and restoring beliefs against persuasion. Sociometry 24, no. 2: 184-97.

- 1962. Persistence of the resistance to persuasion induced by various types of prior belief defenses. Journal of Abnormal and Social Psychology 64, no. 4: 241-8.

McGuire, W., and D. Papageorgis. 1961. The generality of immunity to persuasion produced by preexposure to weakened counter arguments. Journal of Abnormal and Social Psychology 62, no. 3: $475-81$.

. 1962. Effectiveness of forewarning in developing resistance to persuasion. Public Opinion Quarterly 26, no. 1: 24-34.

Moore, D., W. Harris, and H. Chen. 1994. Exploring the role of individual differences in affect intensity on the consumer's response to advertising appeals. Advances in Consumer Research 21: $181-7$. 
Olney, T., M. Holbrook, and R. Batra. 1991. Consumer responses to advertising: The effects of ad content, emotions and attitude toward the ad on viewing time. Journal of Consumer Research 17, no. 4: 440-53.

Papageorgis, D. 1968. Warning and persuasion. Psychological Bulletin 70: 271-82.

Peters, E., I. Lipkus, and M. Diefenbach. 2006. The functions of affect in health communication and in the construction of health preferences. Journal of Communication 56, no. 1: 140-62.

Petty, R., and J. Cacioppo. 1977. Forewarning, cognitive responding, and resistance to persuasion. Journal of Personality and Social Psychology 35, no. 9: 645-55.

1979. Effects of forewarning of persuasive intent and involvement on cognitive responses and persuasion. Personality and Social Psychology Bulletin 5: 173-6.

Pfau, M., H. Wan, E. Szabo, J. Anderson, J. Morrill, and J. Zubric. 2001. The role and impact of affect in the process of resistance to persuasion. Human Communication Research 27, no. 2: $216-52$.

Pham, M.T. 1998. Representativeness, relevance, and the use of feelings in decision making. Journal of Consumer Research 25, no. 2: 144-59.

Schwarz, N., and G. Clore. 1983. Mood, misattribution, and judgments of well-being: Informative and directive functions of affective states. Journal of Personality and Social Psychology 45, no. 3: 513-23.

Weinberger, M., C. Allen, and W. Dillon. 1981. The impact of negative marketing communications: The Consumers Union/Chrysler controversy. Journal of Advertising 10, no. 4: 20-47. 